\title{
Investor Sentiment and Crash Risk in Safe Havens
}

\author{
Adnen Ben Nasr'1, Matteo Bonato², Riza Demirer ${ }^{3}$, Rangan Gupta ${ }^{4}$ \\ ${ }^{1}$ BESTMOD, Institute Supérieur de Gestion de Tunis, Université de Tunis, Tunisia \\ ${ }^{2}$ Department of Economics and Econometrics, University of Johannesburg, Auckland Park, South Africa \\ ${ }^{3}$ Department of Economics \& Finance, Southern Illinois University Edwardsville, Edwardsville, USA \\ ${ }^{4}$ Department of Economics, University of Pretoria, Pretoria, South Africa \\ adnen.bennasr@isg.rnu.tn,mbonato@uj.ac.za,rdemire@siue.edu, Rangan.Gupta@up.ac.za
}

\begin{abstract}
This study examines the relationship between investor sentiment and intraday return dynamics for safe haven assets, with a particular focus on crash risk in these assets. Examining intraday returns for a wide range of safe havens proposed in the literature, we find that shocks to investor sentiment have a significant effect on safest havens, while the sentiment is heterogeneous both in terms of its size and direction. While the strongest effects of sentiment shocks are observed in the case of Gold, Swiss Francs and Japanese Yen, interestingly, we find that oil stands out from the rest of the pack, responding negatively to sentiment shocks, suggesting that positive shocks to sentiment (i.e. high fear) increase crash risk for this asset. Our findings also point to intra-safe haven spillover effects, with oil exhibiting a markedly different pattern. Investment and hedging implications are discussed next.
\end{abstract}

Keywords: Investor sentiment, Safe haven assets, intraday returns, Crash risk.

\section{Introduction}

Research on safe haven assets has recently gained momentum, particularly following the $2007 / 2008$ global financial crisis. As a result, numerous studies over the past several years examined the safe haven and hedging benefits of alternative assets for stock and bond investors, particularly during periods of market turbulence. ${ }^{1}$ Clearly, wild fluctuations in risk sentiment during market turbulence periods present a great challenge for corporations and domestic investors alike regarding the management of currency, stock and commodity market risk exposures. In fact, the relationship between investor sentiment and financial market returns is already well-established in the literature (see (Huang, Jiang, Tu, \& Zhou, 2015) for a detailed literature review). Numerous studies document evidence of a sentiment effect on asset prices, linking sentiment changes to greater mispricing and excess volatility (De Long, Shleifer, Summers, \& Waldmann, 1990), to mutual fund flows out of equity into bond funds (Da, Engelberg, \& Gao, 2015) and to predictable return patterns due to corrections of overreaction (Baker \& Wurgler, 2006). To that end, enlarging our understanding of the return dynamics in safe haven assets is of interest both from an academic and practical perspective. Despite the renewed interest in safe havens and well-established literature on the sentimentstock market relationship, interestingly, the literature presents limited evidence on how sentiment changes relate to return dynamics for safe haven assets.

Clearly, just like sentiment fluctuations can have an impact on stock returns, safe havens will not be immune from such sentiment effects; thus exploring the sentiment-safe haven relationship can offer valuable insight to the identification of the 'safest' safe haven asset during periods when a safe haven is needed the most. Furthermore, the literature has largely examined the behaviour of safe haven assets with respect to a stock or bond index, without delving into how the return dynamics of safe haven assets evolve during periods of large shocks to the financial system when one would expect wild sentiment changes to occur. The only exception to this is a recent study by (Balcilar, Bonato, Demirer, \& Gupta, 2017) establishing a link between investor sentiment and intraday volatility jumps in the gold market. Building on this evidence, this study examines the role of investor sentiment across a wide range of safe haven assets proposed in the literature and looks into whether or not investor sentiment can also explain crash and bubble risks in these assets. By doing so, this

\footnotetext{
1 The literature defines a safe have as an asset that helps investors preserve capital during periods of uncertainty (Kaul \& Sapp, 2006) or an asset that has zero or negative correlation with risky assets during market downturns ( (Baur \& McDermott, Is gold a safe haven? International evidence, 2010); (Baur \& Lucey, Is Gold a Hedge or a Safe Haven? An Analysis of Stocks, Bonds and Gold, 2010)).
} 
study enlarges our understanding of the return dynamics of safe haven assets, particularly during extreme market conditions, an issue that has great importance when it comes to devising strategies to mitigate the negative effects of market crashes on investors' portfolios.

Building on the literature on safe havens, we examine a wide range of assets including Swiss Franc relative to the US Dollar (CHF), Japanese Yen to the US Dollar (JPY), Gold, Silver, West Texas Intermediate Oil (WTI), 2-, 5-, 10-year US Treasury Notes and US Treasury Bonds as prospective safe havens. Next, following (Kräussl, Lehnert, \& Senulyte், 2016), we use intraday data to compute the conditional skewness of the return distribution of these assets as a proxy for crash risk and relate the computed crash risk to the Financial and Economic Attitudes. Revealed by Search (FEARS) index recently developed by (Da, Engelberg, \& Gao, 2015) as a proxy for investor sentiment. Our findings point to a sentiment effect on intraday return dynamics for most safe havens while the effect is rather heterogeneous, both in terms of the size and the direction. Gold, Swiss Francs and Japanese Yen are found to exhibit the strongest reaction to sentiment shocks with a high level of fear leading to a lower crash risk in these assets. Interestingly, however, we find that WTI stands out from the rest of the pack, responding negatively to sentiment shocks, suggesting that positive shocks to sentiment (i.e. high fear) increase crash risk for this asset. Finally, our findings indicate the presence of intra-safe haven spillover effects, with WTI exhibiting a markedly different pattern from the rest of the pack. The rest of this paper is organized as follows.

\section{Brief Review of the Literature on Safe Havens}

The literature has generally considered gold as the traditionally accepted safe haven. Consequently, numerous studies have looked into the safe haven benefits of gold for stock and/or bond investors ( (Capie, Mills, \& Wood, 2005); (Baur \& Lucey, Is Gold a Hedge or a Safe Haven? An Analysis of Stocks, Bonds and Gold, 2010); (Baur \& McDermott, Is gold a safe haven? International evidence, 2010);(Hood \& Malik, 2013); (Reboredo, 2013); and (Bredin, Conlon, \& Poti, 2015)). In other studies, including (Ciner, Gurdgiev, \& Lucey, 2013) and (Agyei-Ampomah, Gounopoulos, \& Mazouz, 2014), the set of prospective safe havens has expanded to other assets including oil, currencies and industrial metals. These studies have generally produced evidence in favour of gold as a safe haven and /or hedge for financial investors, while exceptions are documented in some cases [e.g. (Hood \& Malik, 2013) in favor of VIX; (Agyei-Ampomah, Gounopoulos, \& Mazouz, 2014) in favor of industrial metals]. On the other hand, studies including (Ranaldo \& Soderlind, 2010) and (Grisse \& Nitschka, 2015) have focused on the so-called safe haven currencies that can be used to hedge portfolio values against global risks.

Section 2 provides a brief review of the literature on safe havens. Section 3 presents the data and the econometric framework. Section 4 presents the discussion of the empirical findings; and Section 5 concludes the paper. While (Grisse \& Nitschka, 2015) show that the Swiss franc exhibits safe haven characteristics against many, but not all other currencies, the finding in (Fatum \& Yamamoto, 2016) point to the JPY as the strongest safe haven currency that appreciates as market uncertainty increases regardless of the prevailing level of uncertainty. Despite the multitude of studies on various safe havens, the literature does not provide a clear-cut answer as to which asset is the 'safest' safe haven. To that end, our study contributes to this strand of the literature from a different perspective by examining the intraday behaviour of various safe haven assets with respect the level of investor sentiment and relating sentiment to crash risks. We then extend our analysis to examine intra-safe haven behaviour by exploring how crash risks are related across various safe havens considered in the literature.

\section{Data and Methodology}

Data: Our intraday dataset includes futures prices for various safe haven assets in a continuous format, obtained from disktrading.com. Close to the expiration of a contract, the position is rolled over to the next available contract, provided that activity has increased. Our dataset spans the period $1^{\text {st }} J u l y, 2004$ to $25^{\text {th }}$ March, 2011 using 1-minute frequency data. Futures are traded in NYMEX over a 24-hour trading day (pit and electronic) and the minute frequency is constructed using the last price that occurs in the 1-minute interval. Based on the literature on safe havens, we consider future contracts for a wide range of assets including Swiss Franc relative to the US Dollar (CHF), Japanese Yen to the US Dollar (JPY), Gold, Silver, West 
Texas Intermediate oil (WTI), 2-, 5-, 10-year US Treasury Notes and US Treasury Bonds (i.e., ZTM1, ZNM1, TN10, and TB30, respectively). As mentioned earlier, following (Kräussl, Lehnert, \& Senulytė, 2016), we use intraday data to compute the conditional skewness of the return distribution of each safe haven as a proxy for crash risk. So, using the 1-minute frequency data, we then calculate for each asset, the realized skewness $\left(R S K_{t}\right)$ on day $\mathrm{t}$ as

$$
R S K_{t}=\frac{\sqrt{N} \sum_{i=1}^{N}\left(r_{i, t}\right)^{3}}{R V_{t}^{3 / 2}}
$$

Where, $N$ is the number of intra-day returns $\left(r_{i, t}\right)$ on day $t$ and $R V_{t}$ is the measure of realized volatility, i.e., $R V_{t}=\sum_{i=1}^{N}\left(r_{i, t}\right)^{2}$. Note that even though we use daily frequency data in our empirical analysis as investor sentiment data is available on a daily frequency. The results obtained with the intraday data provide valuable insight into the intraday return dynamics. In the case of our proxy for investor sentiment we use the Financial and Economic Attitudes Revealed by Search (FEARS30) index recently developed by (Da, Engelberg, \& Gao, 2015). Is shown to predict short-term return reversals, temporary increases in volatility and mutual fund flows from equity funds into bond funds this index utilizes daily Internet search data from a large number of households in the U.S. with a focus on particular sentiment-revealing keywords such as 'recession' or 'unemployment' and proxies the level of the sentiment of American households by aggregating the search data across economy-related keywords. ${ }^{2}$ After the removal of obvious holidays, days with limited market hours (e.g. December 24), and matching the data with the investor sentiment index, we are left with 1,685 observations. It is important to point out that the sample period is governed by the availability of the daily investor sentiment data, which in turn, plays an integral part in economthe etric analysis. Note that while, there are other existing daily investor sentiment indexes, they are not publicly available as the FEARS30, and hence, needs to be purchased at a massive expense. Other freely available investor sentiment indexes (see for example, (Baker \& Wurgler, 2006) and (Huang, Jiang, Tu, \& Zhou, 2015)) ${ }^{3}$ are however, only at monthly frequencies.

Econometric Framework: To examine the spillover effect between investor sentiment and realized skewness (and intra-safe haven dynamics) as well as its feedback on investor sentiment if any, we employ the impulse response analysis within a vector autoregressive (VAR) framework. The $k$-dimensional VAR model is expressed under the form of the following equation:

$$
Y_{t}=v+A_{1} Y_{t-1}+\cdots+A_{p} Y_{t-p}+\varepsilon_{t}
$$

Where, $Y_{t}$ is the $k x 1$ vector of variables on day $t, c$ is the $k x 1$ vector for the intercept, $A$ is the $k x k$ matrix of coefficients, and $\varepsilon_{t}$ is the $k x 1$ vector of the error term. $\operatorname{Lag} p(=8)$ is chosen based on the likelihood ratio (LR) test. Since the other lag-length tests, including Final prediction error criterion (FPEC), Akaike information criterion (AIC), Schwarz information criterion (SIC), and Hannan-Quinn information criterion (HQIC) suggest $p=0$, we also conduct a regression analysis, with inferences based on (Newey \& West, 1987) heteroskedasticity and autocorrelation consistent (HAC) standard errors. After fitting a VAR with the ordinary least squares (OLS) method, we conduct the generalized impulse response (GIR) analysis proposed by (Pesaran \& Shin, 1998) since there is no clear economic guidance on the direction of the instantaneous causality between the variables in the VAR. (Pesaran \& Shin, 1998) show that generalized responses of the system at time $t+h$ to one-standard-deviation exogenous shock to the jth variable at time $t$ can be calculated as,

$$
\hat{\theta}_{j}(h)=\sigma_{j j}^{-\frac{1}{2}} \prod_{h} \sum_{\varepsilon} e_{j} \quad h=0,1,2, \ldots
$$

Where, $\sum_{\varepsilon}=\left\{\sigma_{i j} ; i, j=1,2, \ldots, k\right\}$ is the $k x k$ variance-covariance matrix of error term $\varepsilon_{t}$, and $e_{j}$ is a $k x 1$ selection vector with unity as its $j$ th element and zeros elsewhere. $\prod_{i}$ Is the $k x k$ matrix of coefficients generated from infinite moving average representation of model (3) and it can be computed recursively using as,

\footnotetext{
2 The data is available for download from: http://www3.nd.edu/ zda/fears_post_20140512.csv.

3 The data are available at: http://people.stern.nyu.edu/jwurgler/ and http://apps.olin.wustl.edu/faculty/zhou/.
} 


$$
\Pi_{i}=\left\{\begin{array}{cc}
\sum_{j=1}^{i} \prod_{i-j} A_{j} & i=1,2, \ldots p \\
\sum_{j=1}^{p} \prod_{i-j} A_{j} & i>p
\end{array}\right.
$$

Where $\prod_{0}=I_{K}$, a $k$-dimensional identity matrix, finally we make inferences regarding the presence of a spill over effect by constructing the 95 percent bias-corrected bootstrap confidence interval for the GIR, as discussed in (Efron \& Tibshirani, 1993).

\section{Empirical Results}

Regression Models: Table 1 summarizes the response of the realized skewness of intraday returns for each safe haven to investor sentiment (FEARS30) and the realized skewness for the other safe havens. The column (Resp.) in the table reports the response estimate in the regression model in Equation (2). We observe a significant sentiment effect on safe haven assets, particularly in the case of the Swiss Franc and Gold with a relatively weaker effect on the Yen. Interestingly, however, the positive (negative) coefficient observed for Gold and CHF (JPY) suggest that sentiment. Changes are likely to serve as a predictor of positive bubbles for $\mathrm{CHF}$ and Gold, while sentiment has predictive power over negative bubbles in the case of JPY.

The sentiment effect on gold is in fact consistent with the recent findings in (Balcilar, Bonato, Demirer, \& Gupta, 2017) that changes in investor sentiment are associated with jumps in intraday volatility. We also observe in Table 1 noteworthy intra-safe haven effects, particularly across Gold, CHF and Yen, implied by a positive relationship among their intraday realized skewness values. US Treasury securities, on the other hand, seem to be following an independent pattern with a positive feedback structure in their crash risks. Overall, the evidence from regression models suggests a sentiment effect particularly on three major safe havens, i.e. Gold, Swiss Francs and Japanese Yen, with some evidence of intra-safe haven feedback mechanism observed. Given the evidence from the asset pricing literature of investors' preference for positive skewness (e.g. (Mitton \& Vorkink, 2007); (Barberis \& Huang, 2008)), these findings suggest that sensitivity of these assets with respect to investor sentiment could be utilized in selective hedging strategies in order to mitigate the negative effects of financial shocks more effectively

\section{[INSERT TABLE 1]}

Generalized Impulse Response Analysis: We now turn our attention to the results from the GIRFs derived from the VAR model due to shocks to investor sentiment (FEARS30) as formulated in Equation 3. As shown in Figure 1, generally, all safe haven assets respond positively to a shock in investor sentiment with the exception of WTI. The strongest effect is observed on the realized skewness of intraday Gold returns, consistent with the earlier findings of (Balcilar, Bonato, Demirer, \& Gupta, 2017). It can be argued that the positive response of intraday skewness to sentiment shocks is driven by fund flows into safe haven assets during periods of high market stress, driving the prices of these assets higher due to increased demand (and thus the positive response in intraday skewness). The negative effect in the case of crude oil (WTI), however, can be due to the increased association of oil and stock markets (as noted by (Bernanke, 2016)), driving oil returns to follow a similar pattern to that of the stock market as both markets react to a common systematic risk factor reflecting global aggregate demand and economic growth expectations. The effect of sentiment shocks, however, is generally found to be short-lived, lasting for about two days.

The GIRFs due to shocks to each safe haven asset, presented in Figures 2-10, further confirm prior results, indicating the presence of intra-safe haven dynamics at play. Shocks to Gold, JPY and Treasury Bonds (TB30) are generally followed by responses in the same direction by other safe havens. The strongest effect is generally observed on shorter-term US Treasury securities in our list, ZNM1 and ZTM1, reflecting the market's preference for liquidity and investors' seek for relatively safe, dollar-denominated assets during periods of market stress, captured by sentiment shocks. Once again, WTI stands out as an exception, responding negatively to positive shocks to other safe haven assets.

[INSERT FIGURES 1 TO 10] 
In sum, our findings point to a significant sentiment effect on most safe havens, while the effect is not necessarily homogeneous across these assets. In particular, crude oil seems to stand out from the rest of the safe haven assets, exhibiting a markedly different response to sentiment shocks, consistent with the argument by (Bernanke, 2016) that oil and stock markets have recently followed an increasingly similar pattern due to their common sensitivity to global growth expectations. To that end, our findings suggest that oil should not necessarily be classified as a safe haven asset that investors can utilize during periods of market stress.

\section{Conclusion}

The literature on safe havens has experienced tremendous growth over the past decade, particularly following the historic market turbulence experienced during the global financial crisis of $2007 / 08$. This paper enlarges our understanding of safe haven return dynamics by examining the effect of investor sentiment on crash risks in safe haven assets. While the effect of investor sentiment is well-documented for stock returns, the analysis has not yet been extended to safe haven assets and in the context of crash risks. Following (Kräussl, Lehnert, \& Senulytè, 2016), we use intraday data and compute the conditional skewness of the return distribution of a wide range of safe havens as a proxy for crash risk and examine the spillover effect between investor sentiment and realized skewness for Swiss Franc relative to the US Dollar (CHF), Japanese Yen to the US Dollar (JPY), Gold, Silver, West Texas Intermediate oil (WTI), 2-, 5-, 10-year US Treasury Notes and US Treasury Bonds (i.e., ZTM1, ZNM1, TN10, and TB30, respectively).

Our findings point to a sentiment effect on intraday return dynamics for most safe havens while the effect is rather heterogeneous, both in terms of the size and the direction. We observe the strongest effects of sentiment shocks in the case of Gold, Swiss Francs and Japanese Yen, with the effect being positive, underscoring the increased demand for these assets. During periods of market turbulence and hence driving their prices higher, possibly leading to positive bubbles interestingly, however, we find that WTI stands out from the rest of the pack, responding negatively to sentiment shocks, suggesting that positive shocks to sentiment (i.e. high fear) increase crash risk in oil. Finally, we observe that some spillover effects also at play, pointing to an intra-safe haven feedback mechanism, with WTI exhibiting a markedly different pattern from the rest of the pack. These findings have several important implications for practical investment purposes and future research direction. The most important implication of our findings is that one cannot necessarily classify crude oil as a safe haven asset as it behaves more like a risky asset than the traditional safe havens like precious metals or safe currencies like the yen or francs. To that end, our findings confirm the close association between oil and stock markets, recently noted by (Bernanke, 2016). Given this, a risk management strategy would be to use short positions in crude oil to hedge exposures to market risks. Therefore, for future research, it would be interesting to explore the role of crude oil as a hedging tool rather than a safe haven.

Furthermore, given the finding that not all safe havens are alike in terms of their responses to sentiment shocks. Risk managers have to closely examine the distributional characteristics of alternative safe havens in order to identify the 'safest' safe haven that will yield the most effective results. Considering the finding of intra-safe haven interactions and the similarity in their responses to sentiment shocks, one can argue that all of the assets we examined (with the exception of crude oil) will offer some degree of safe haven benefits to investors during periods of market stress. Therefore, risk managers can determine the least costly portfolio immunization strategy by building on the findings reported for the safe havens in our sample. Finally, considering the recent finding by (Fernandez-Perez, Frijns, Fuertes, \& Miffre, 2018) that a skewness factor can explain the cross-section of commodity returns beyond standard risk exposures, our finding of a sentiment effect on intraday skewness, consistently across the safe havens in our list, suggests that the sensitivity of commodities to changes in investor sentiment may in fact be the driving factor behind the skewness premium documented recently. If that is indeed the case, an active commodity investment strategy conditional on a commodity's sensitivity to investor sentiment may be implemented in order to generate abnormal returns. In short, our findings provide novel insight into the strand of the literature on safe havens with potential investment implications. 


\section{References}

Agyei-Ampomah, S., Gounopoulos, D. \& Mazouz, K. (2014). Does gold offer better protection against losses in sovereign debt bonds than other metals? Journal of Banking \& Finance, 40, 507-521.

Baker, M. \& Wurgler, J. (2006). Investor sentiment and the cross-section of stock returns. Journal of Finance, $61,1645-1680$.

Balcilar, M., Bonato, M., Demirer, R. \& Gupta, R. (2017). The effect of investor sentiment on gold market return dynamics: Evidence from a nonparametric causality-in-quantiles approach. Resources Policy, 51, 7784.

Barberis, N. \& Huang, M. (2008). Stocks as lotteries: the implications of probability weighting for security prices. American Economic Review, 98, 2066-2100.

Baur, D. G. \& Lucey, B. M. (2010). Is Gold a Hedge or a Safe Haven? An Analysis of Stocks, Bonds and Gold. The Financial Review, 45, 217-229.

Baur, D. G. \& McDermott, T. K. (2010). Is gold a safe haven? International evidence. Journal of Banking and Finance, 34, 1886-1898.

Bernanke, B. (2016). The relationship between stocks and oil prices. Retrieved from Brookings: https://www.brookings.edu/blog/ben-bernanke/2016/02/19/the-relationship-between-stocksand-oil-prices/

Bredin, D., Conlon, T. \& Poti, V. (2015). Does gold glitter in the long-run? Gold as a hedge and safe haven across time and investment horizon. International Review of Financial Analysis, 41, 320-328.

Capie, F., Mills, T. C. \& Wood, G. (2005). Gold as a hedge against the dollar. Journal of International Financial Markets Institutions and Money, 15(4), 343-352.

Ciner, C., Gurdgiev, C. \& Lucey, B. M. (2013). Hedges and safe havens: An examination of stocks, bonds, gold, oil and exchange rates. International Review of Financial Analysis, 29, 202-211.

Da, Z., Engelberg, J. \& Gao, P. (2015). The Sum of All FEARS Investor Sentiment and Asset Prices. Review of Financial Studies, 28(1), 1-32.

De Long, J. B., Shleifer, A., Summers, L. H. \& Waldmann, R. J. (1990). Noise trader risk in Financial markets. Journal of Political Economy, 98, 703-738.

Efron, B. \& Tibshirani, R. J. (1993). An Introduction to the Bootstrap. New York: Chapman \& Hall.

Fatum, R. \& Yamamoto, Y. (2016). Intra-safe haven currency behavior during the global financial crisis. Journal of International Money and Finance, 66, 49-64.

Fernandez-Perez, A., Frijns, B., Fuertes, A. \& Miffre, J. (2018). The skewness of commodity futures returns. Journal of Banking and Finance, 86, 143-158.

Grisse, C. \& Nitschka, T. (2015). On financial risk and the safe haven characteristics of Swiss franc exchange rates. Journal of Empirical Finance, 32, 153-164.

Hood, M. \& Malik, F. (2013). Is gold the best hedge and a safe haven under changing stock market volatility? Review of Financial Economics, 22, 47-52.

Huang, D., Jiang, F., Tu, J. \& Zhou, G. (2015). Investor sentiment aligned: a powerful predictor of stock returns. Review of Financial Studies, 28, 791-837.

Kaul, A. \& Sapp, S. (2006). Y2K fear and safe haven trading of the US dollar. Journal of International Money and Finance, 25, 760-797.

Kräussl, R., Lehnert, T. \& Senulytė, S. (2016). Euro crash risk. Journal of Empirical Finance, 38, 417-428.

Mitton, T. \& Vorkink, K. (2007). Equilibrium underdiversification and the preference for skewness. The Review of Financial Studies, 20, 1255-1288.

Newey, W. K. \& West, K. D. (1987). A Simple, Positive Semi-definite, Heteroskedasticity and Autocorrelation Consistent Covariance Matrix. Econometrica, 55(3), 703-708.

Pesaran, H. H. \& Shin, Y. (1998). Generalized impulse response analysis in linear multivariate models. Economics Letters, 58, 17-29.

Ranaldo, A. \& Soderlind, P. (2010). Safe Haven Currencies. Review of Finance, 14, 385-407.

Reboredo, J. C. (2013). Is gold a safe haven or a hedge for the US dollar? Implications for risk management. Journal of Banking \& Finance, 37, 2665-2676. 


\section{Figure 1: GIRFS for a Shock to Fears30}

Response to Generalized One S.D. Innovations \pm 2 S.E.

Response of FEARS30 to FEARS30

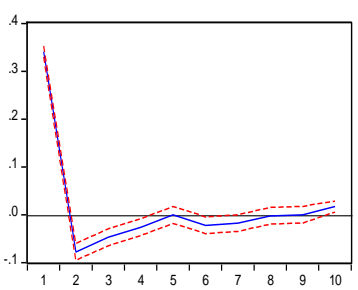

Response of SILVER to FEARS30

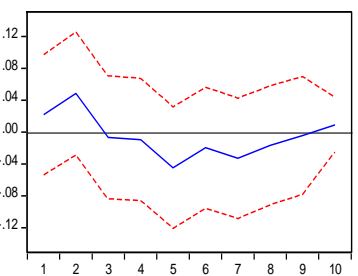

Response of ZNM1 to FEARS30

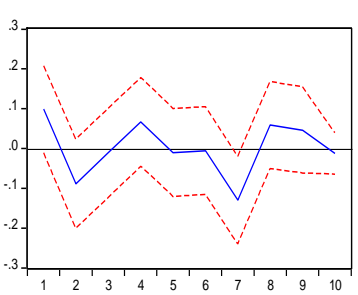

Response of CHF to FEARS30

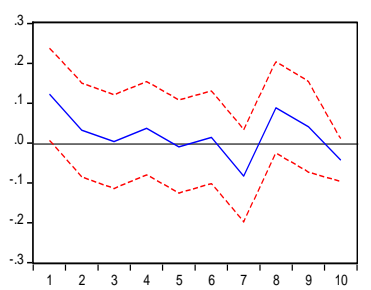

Response of TB30 to FEARS30

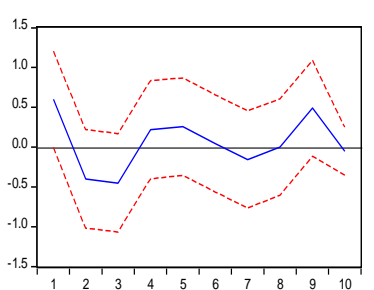

Response of ZTM1 to FEARS30

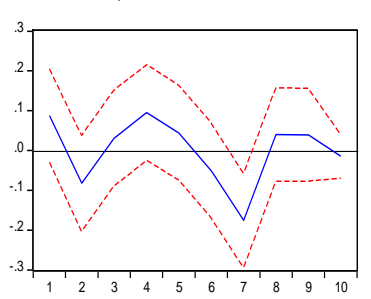

Response of GOLD to FEARS30

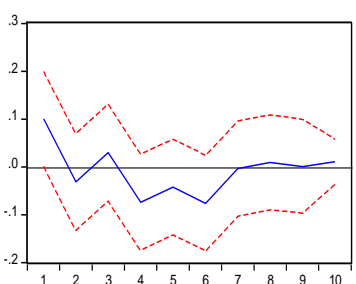

Response of TN10 to FEARS30

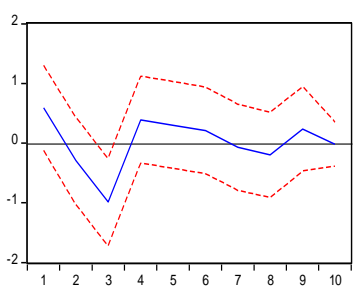

Response of JPY to FEARS30

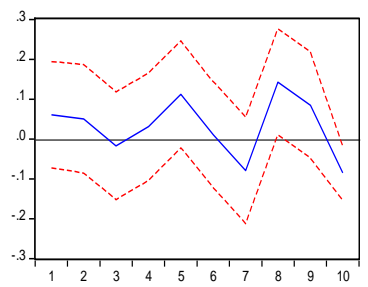

Response of WTI to FEARS30

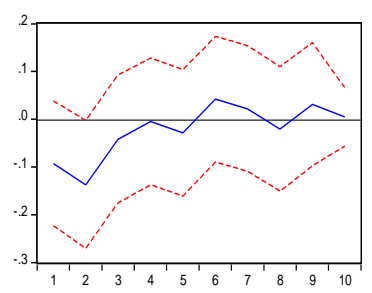

Figure 2: GIRFs for a Shock to CHF

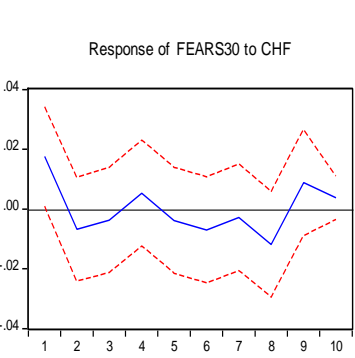

Response to Generalized One S.D. Innovations \pm 2 S.E.

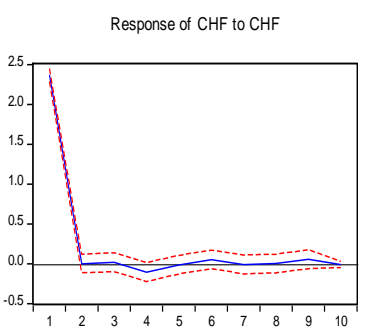

Response of GOLD to CHF

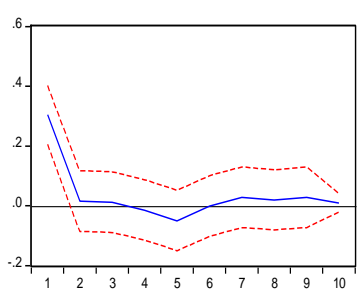

Response of JPY to CHF

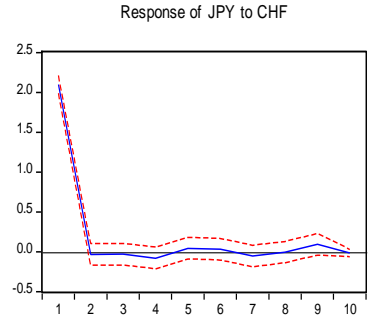

Response of SILVER to CHF

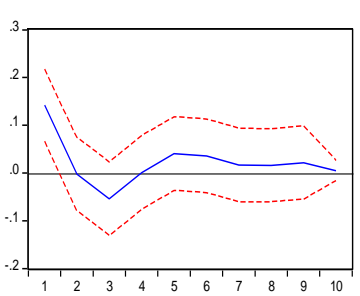

Response of TB30 to CHF

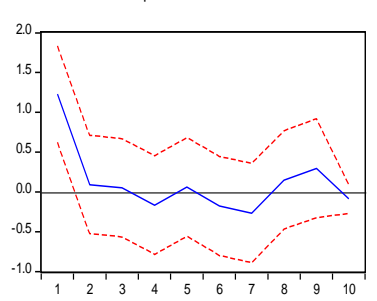

Response of TN10 to CHF

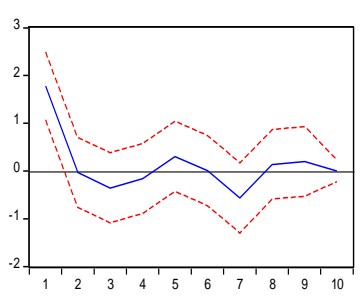

Response of WTI to CHF

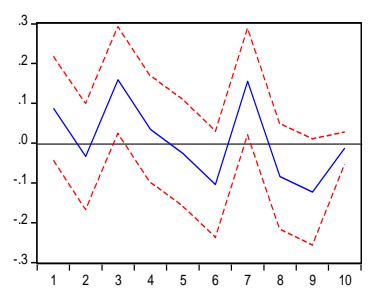

Response of ZNM1 to CHF

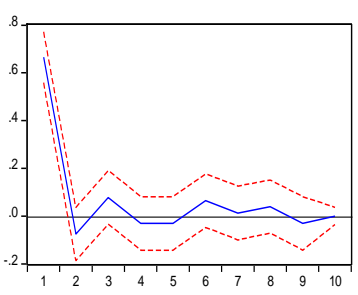

Response of ZTM1 to CHF

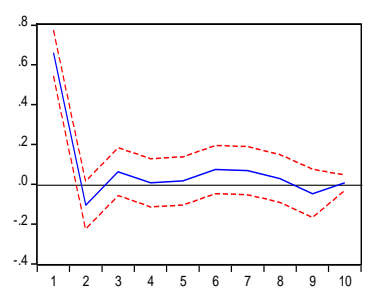




\section{Figure 3: GIRFs for a Shock to Gold}

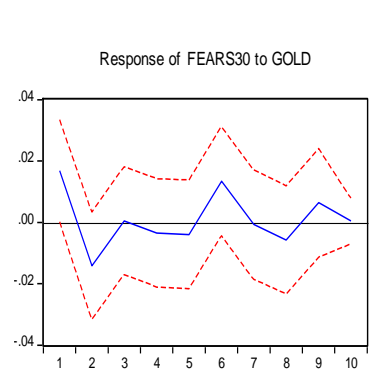

Response to Generalized One S.D. Innovations \pm 2 S.E.

Response of CHF to GOLD

Response of GOLD to GOLD
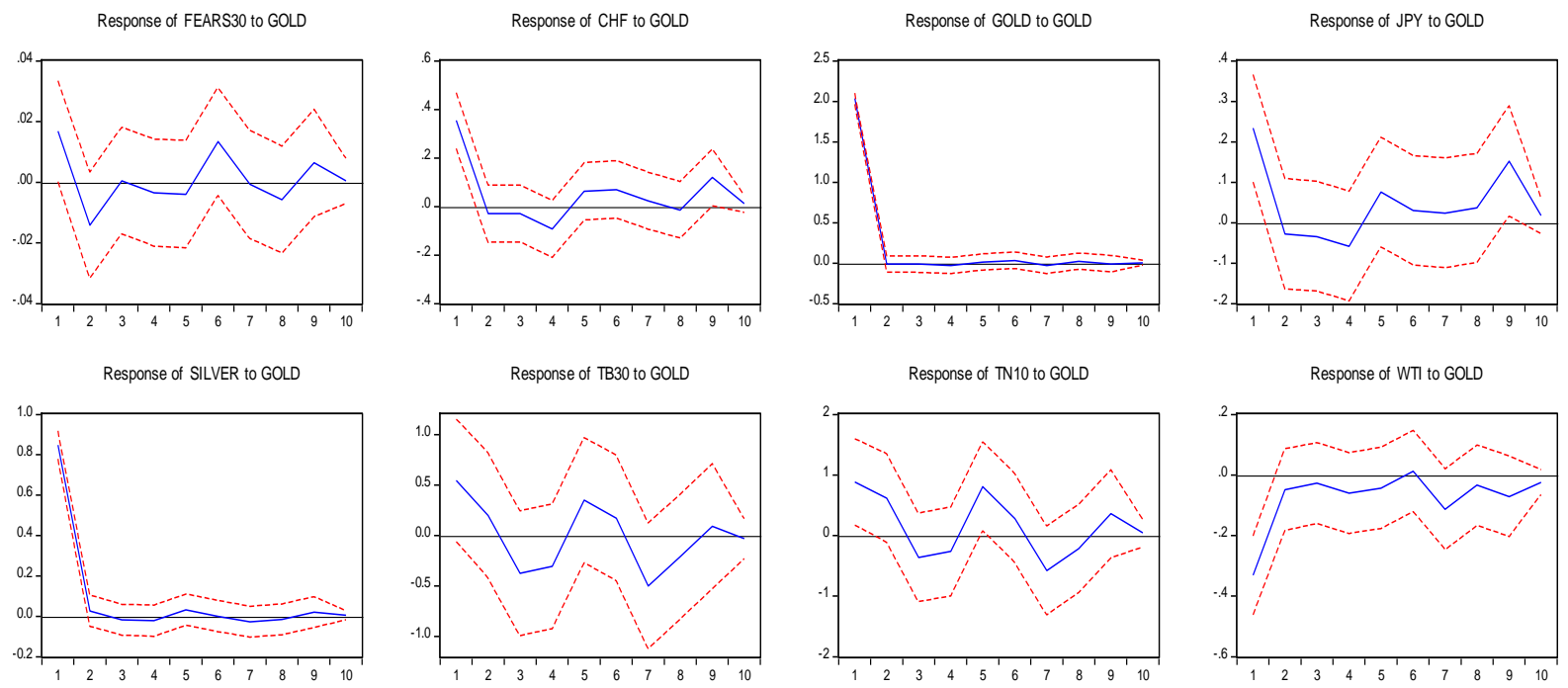

Response of ZNM1 to GOLD
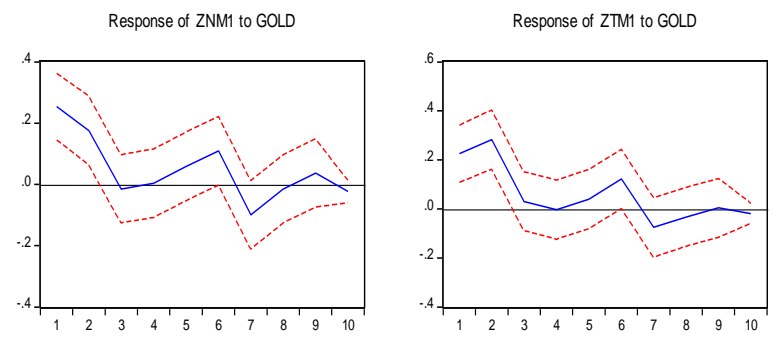

Figure 4: GIRFs for a Shock to JPY

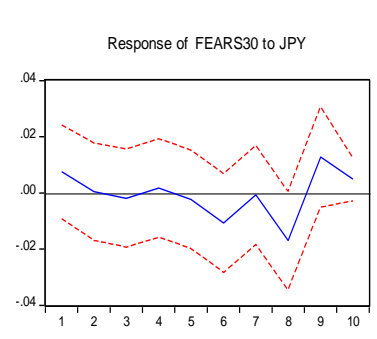

Response to Generalized One S.D. Innovations \pm 2 S.E.
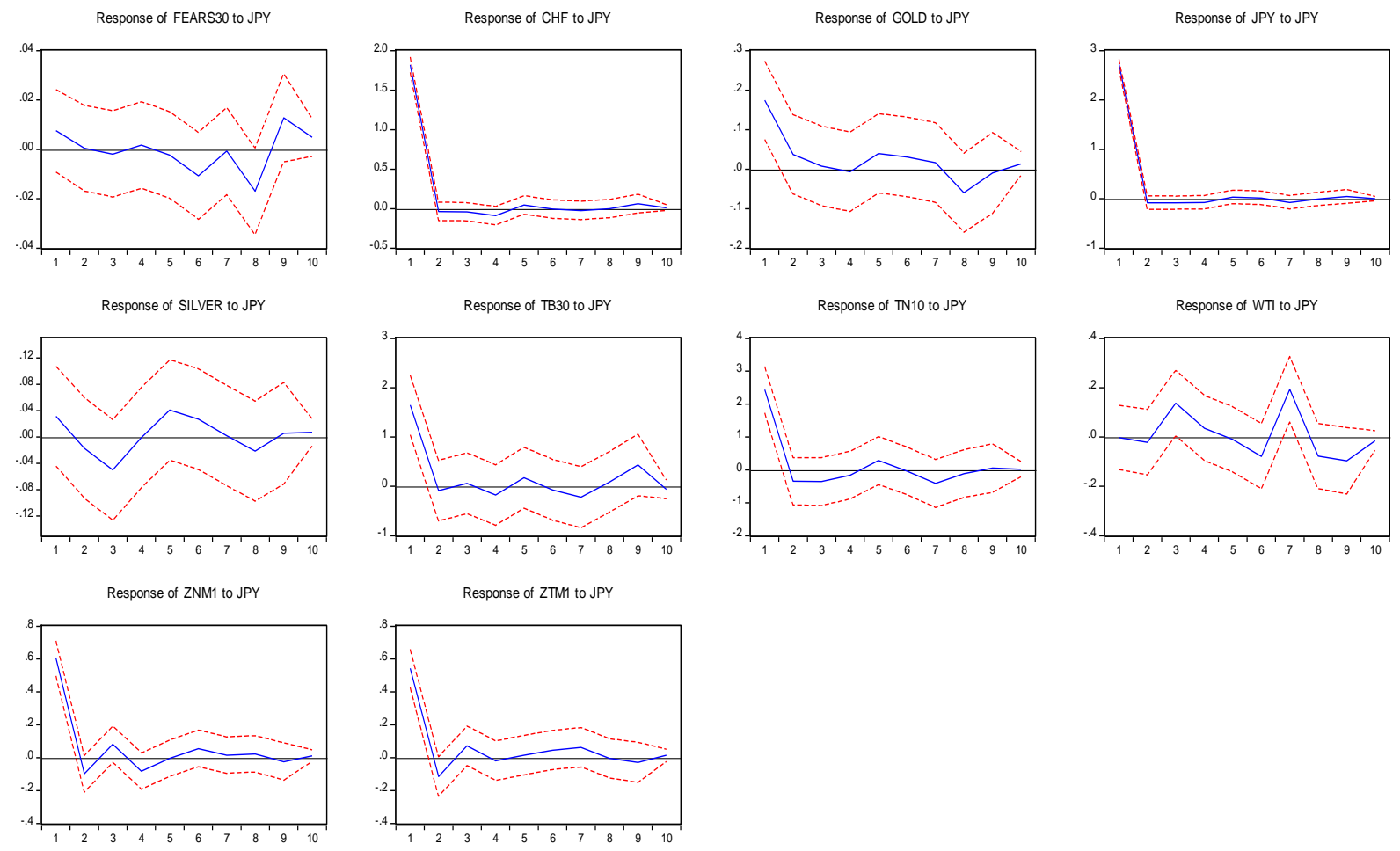


\section{Figure 5: GIRFs for a Shock to Silver}

Response to Generalized One S.D. Innovations \pm 2 S.E.

Response of FEARS30 to SILVER

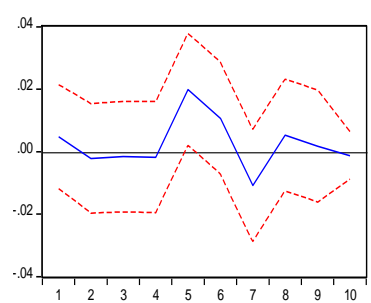

Response of SILVER to SILVER

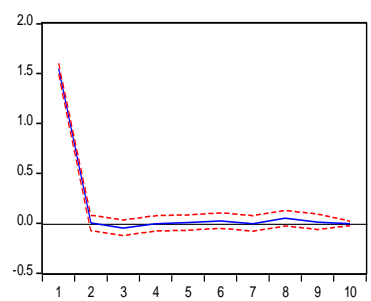

Response of ZNM1 to SILVER

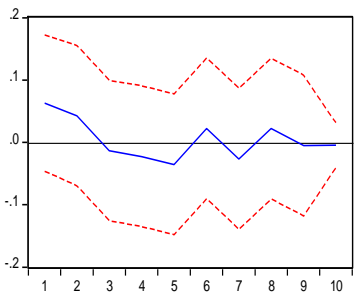

Response of CHF to SILVER

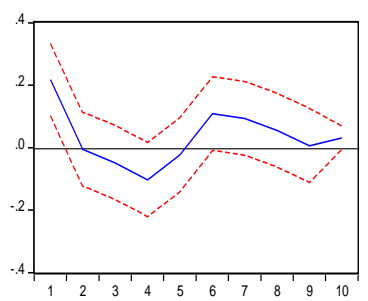

Response of TB30 to SILVER

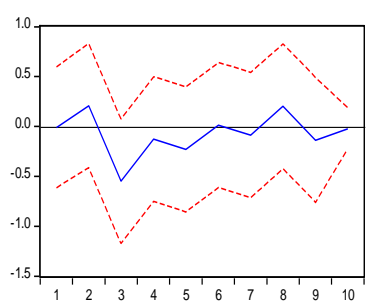

Response of ZTM1 to SILVER

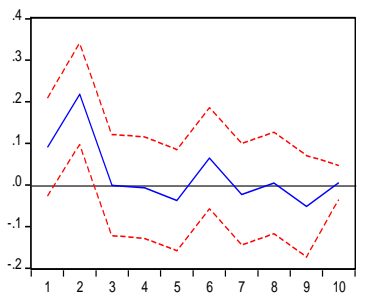

Response of GOLD to SILVER

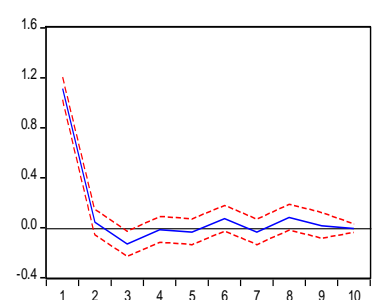

Response of TN10 to SILVER
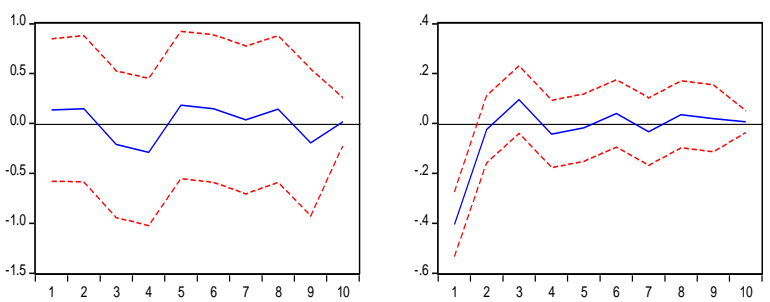

Response of JPY to SILVER

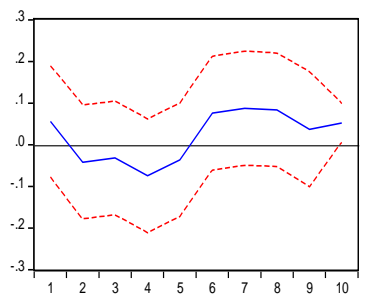

Response of WTI to SILVER

Figure 6: GIRFs for a Shock to TB30

Response of FEARS30 to TB30

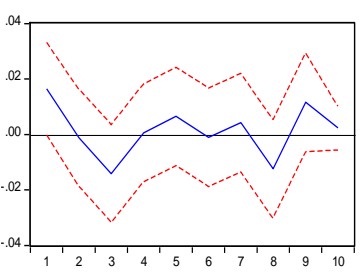

Response of SILVER to TB30

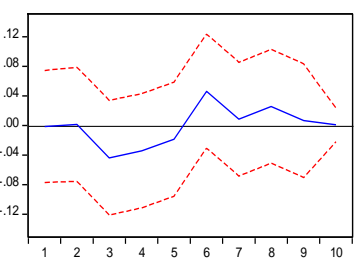

Response of ZNM1 to TB30

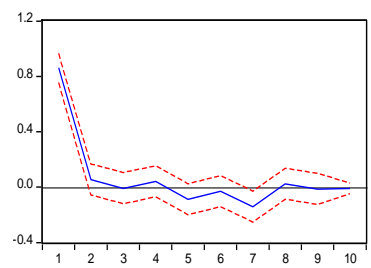

Response to Generalized One S.D. Innovations \pm 2 S.E.

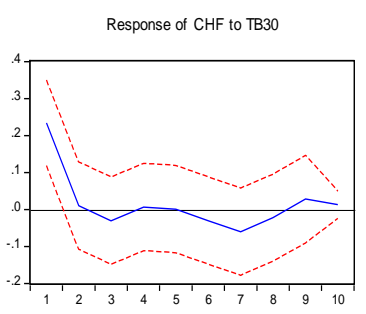

Response of TB30 to TB30

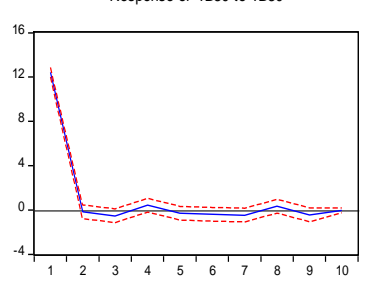

Response of ZTM1 to TB30

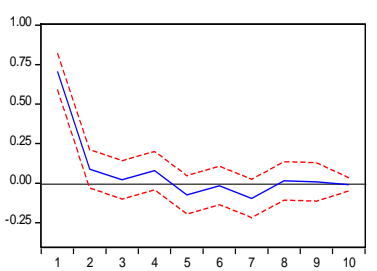

Response of GOLD to TB30

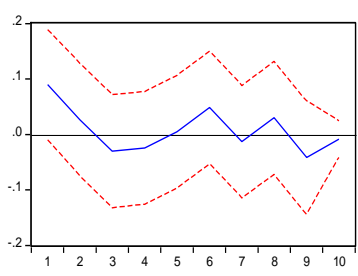

Response of TN10 to TB30

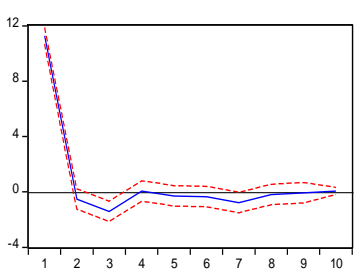

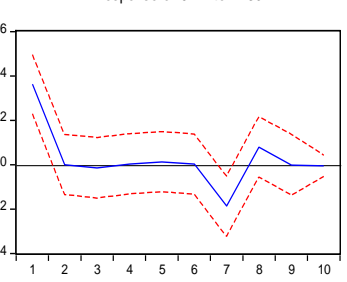

Response of WTI to TB3O

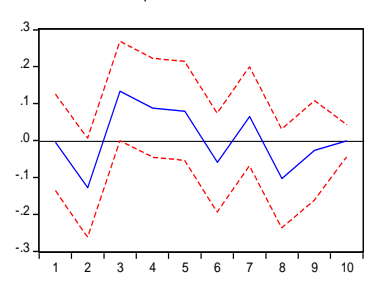




\section{Figure 7: GIRFs for a Shock to TN10}

Response to Generalized One S.D. Innovations \pm 2 S.E.

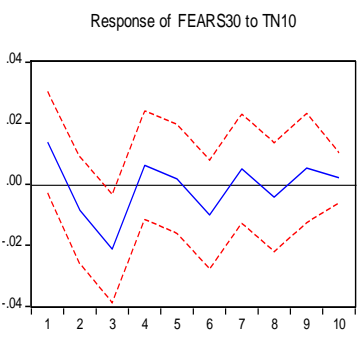

Response of CHF to TN10

Response of GOLD to TN10
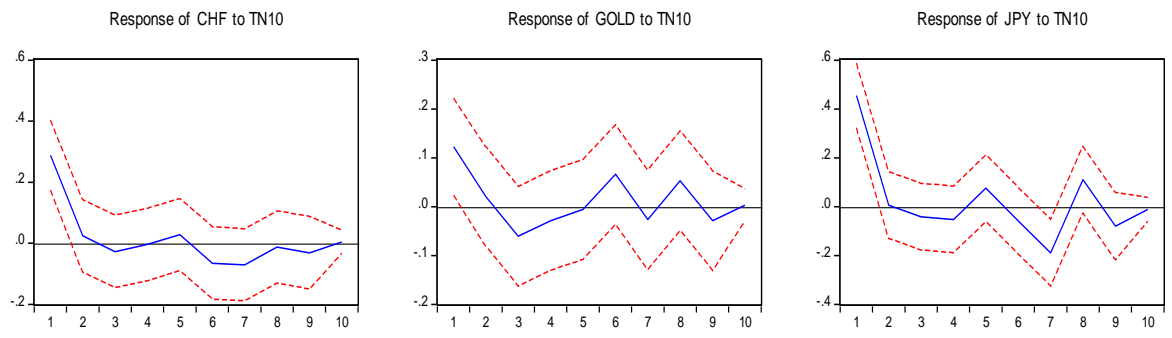

Response of SILVER to TN10

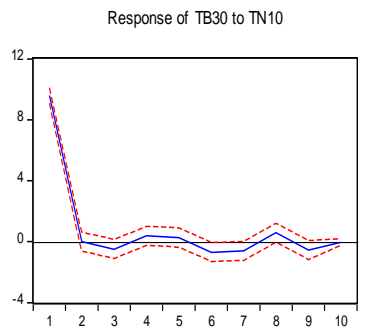

Response of TN10 to TN10

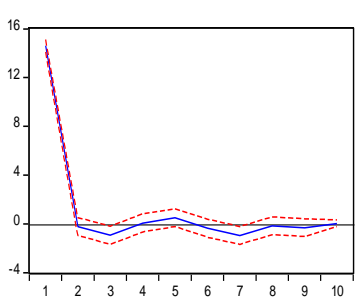

Response of WTI to TN10

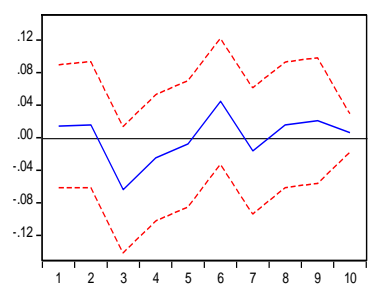

Response of ZNM1 to TN10

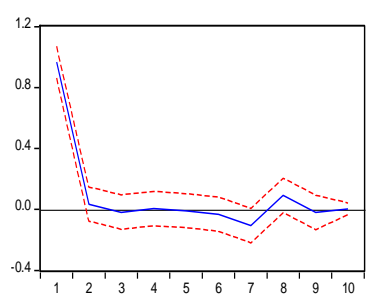

Response of ZTM1 to TN10
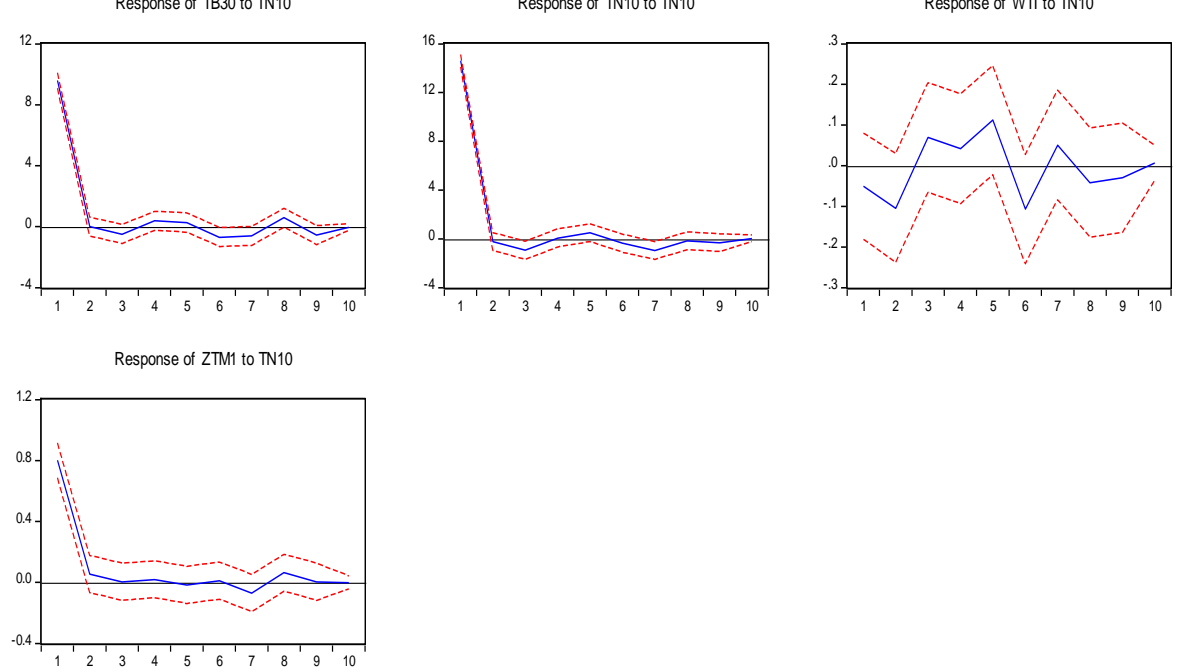

Figure 8: GIRFs for a Shock to WTI
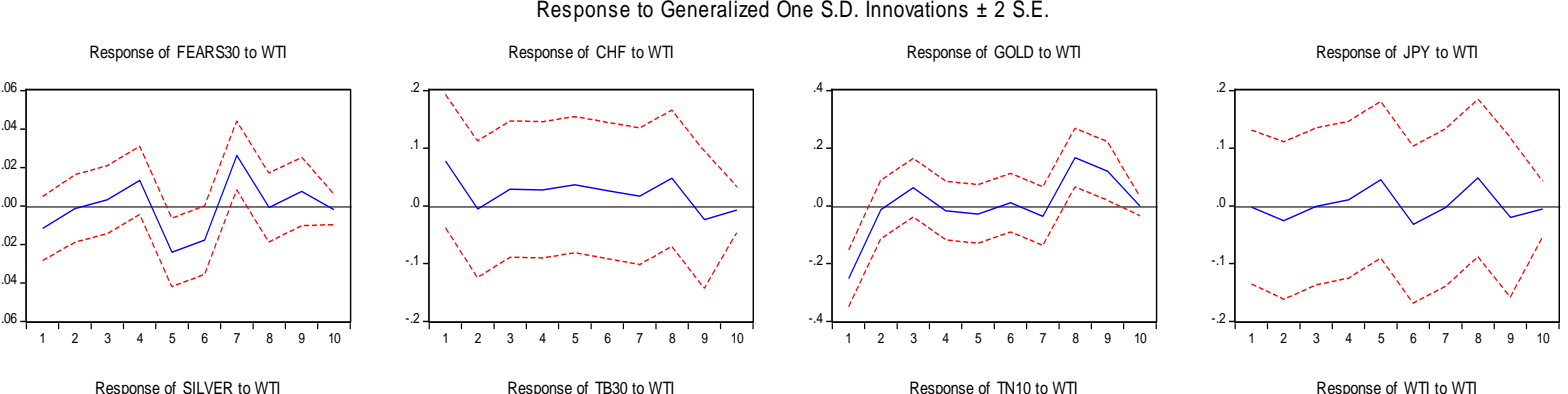

Response or sitv

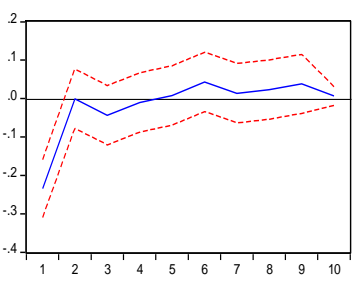

Response of TB30 to WTI

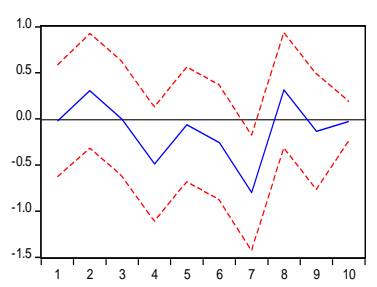

Response of TN10 to WTI

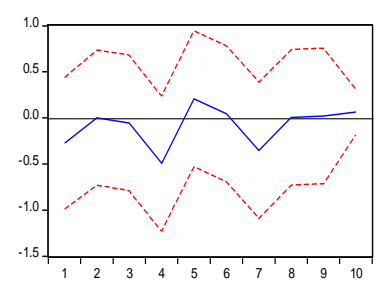

Response of WTI to WT

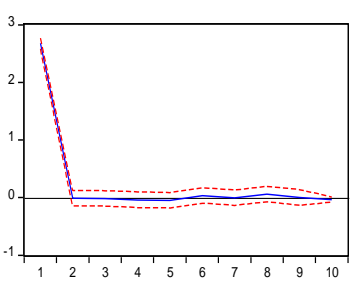

Response of ZNM1 to WTI
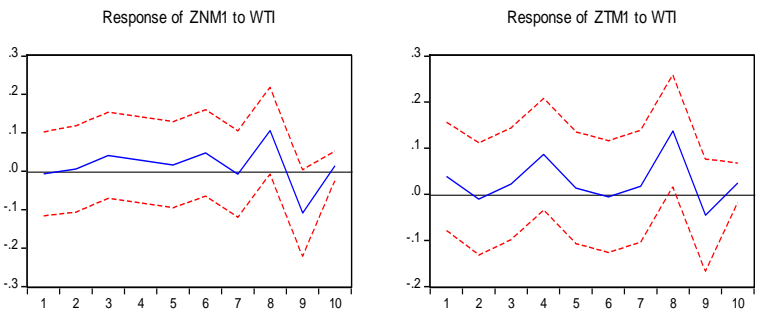


\section{Figure 9: GIRFs for a Shock to ZNM1}

Response to Generalized One S.D. Innovations \pm 2 S.E.

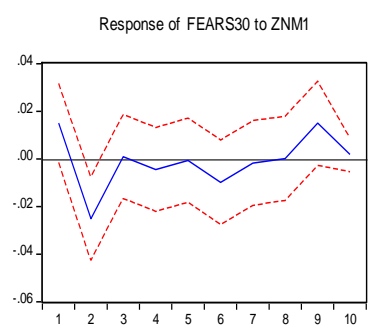

Response of CHF to ZNM

Response of GOLD to ZNM1
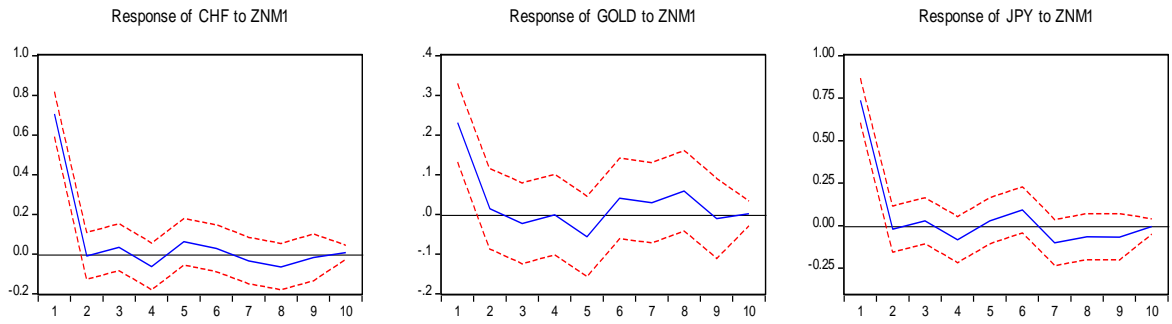

Response of SILVER to ZNM

Response of TB30 to ZNM
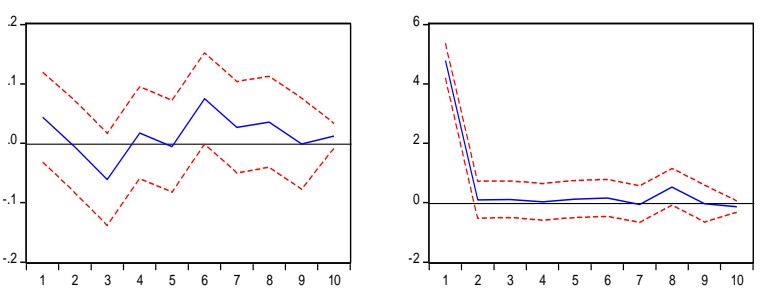

Response of TN10 to ZNM1

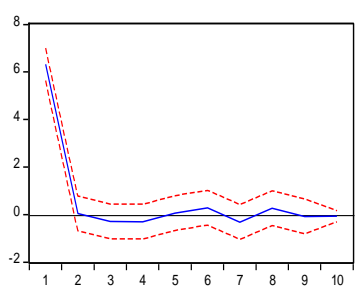

Response of WTI to ZNMI

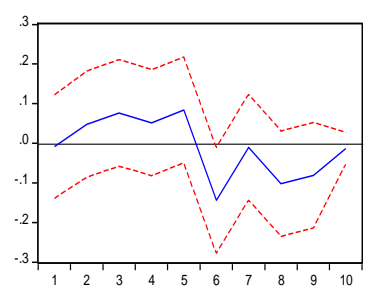

Response of ZNM1 to ZNM1

Response of ZTM1 to ZNM1
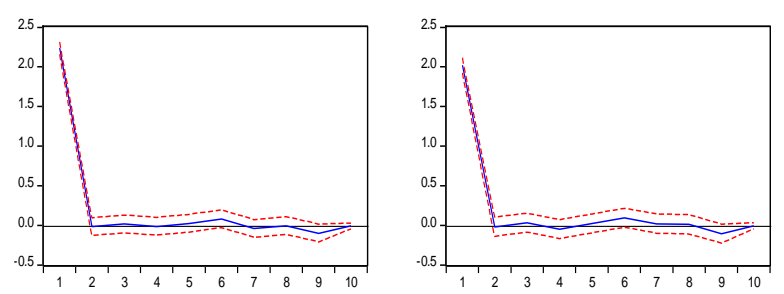

Figure 10: GIRFs for a Shock to ZTM1

Response of FEARS30 to ZTM

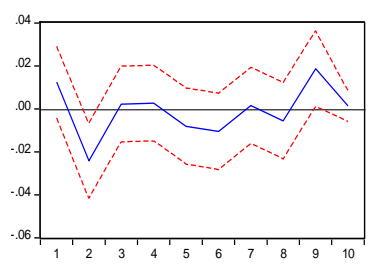

Response of SILVER to ZTM1

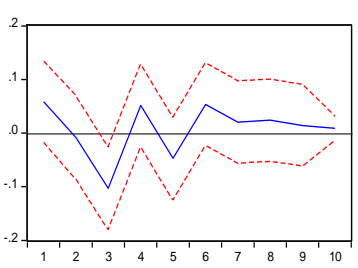

Response of ZNM1 to ZTM1

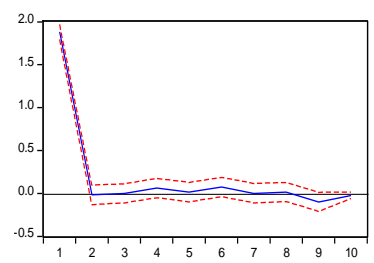

Response to Generalized One S.D. Innovations \pm 2 S.E.

Response of CHF to ZTM1

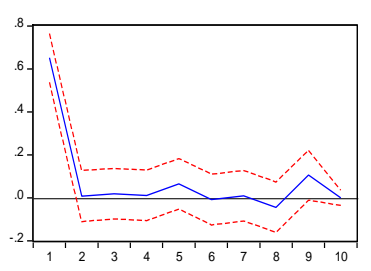

Response of TB30 to ZTM1

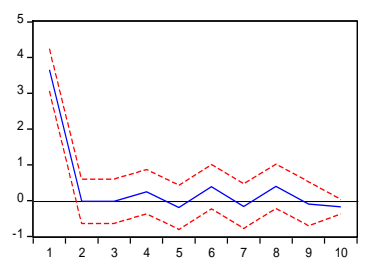

Response of ZTM1 to ZTM

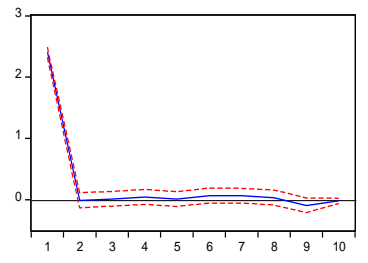

Response of GOLD to ZTM1

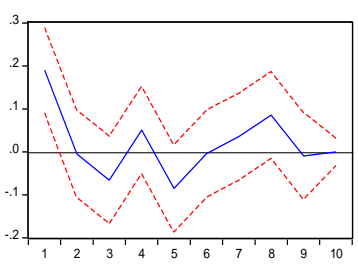

Response of TN10 to ZTM1

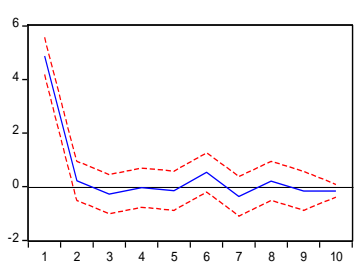

Response of JPY to ZTM1

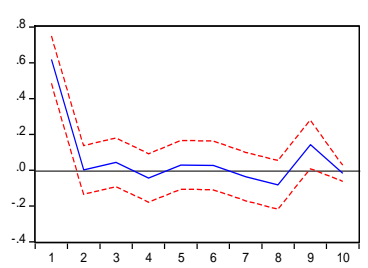

Response of WTI to ZTM1

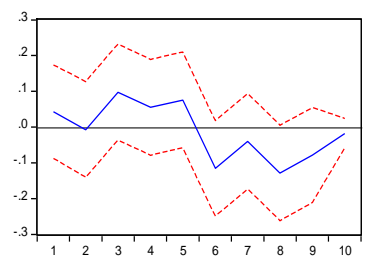


Journal of Economics and Behavioral Studies (ISSN: 2220-6140)

Vol. 10, No. 6A, pp. 97-108, 2018

Table 1: Regressions Results

\begin{tabular}{|c|c|c|c|c|c|c|c|c|c|c|c|c|c|c|c|c|c|c|}
\hline \multirow[t]{2}{*}{ Variable } & \multicolumn{2}{|c|}{ CHF } & \multicolumn{2}{|c|}{ Gold } & \multicolumn{2}{|c|}{ JPY } & \multicolumn{2}{|c|}{ Silver } & \multicolumn{2}{|c|}{ TB30 } & \multicolumn{2}{|c|}{ TN10 } & \multicolumn{2}{|c|}{ WTI } & \multicolumn{2}{|c|}{ ZNM1 } & \multicolumn{2}{|c|}{ ZTM1 } \\
\hline & Resp. & $p$-value & Resp. & $p$-value & Resp. & $p$-value & Resp. & $p$-value & Resp. & $p$-value & Resp. & $p$-value & Resp. & $p$-value & Resp. & $p$-value & Resp. & $p$-value \\
\hline Constant & 0.027 & 0.441 & 0.075 & $0.066^{*}$ & 0.105 & $0.009^{* * *}$ & -0.066 & $0.024^{* *}$ & -0.026 & 0.900 & 0.138 & 0.569 & 0.163 & $0.007^{* * *}$ & -0.103 & $0.000^{* * *}$ & 0.060 & $0.062^{* *}$ \\
\hline FEAR30 & 0.198 & $0.044^{* *}$ & 0.221 & $0.040^{* *}$ & -0.175 & $0.082^{*}$ & -0.086 & 0.328 & 0.620 & 0.333 & -0.004 & 0.996 & -0.139 & 0.266 & 0.000 & 0.997 & 0.019 & 0.777 \\
\hline CHF & -- & -- & 0.090 & $0.002^{* * *}$ & 0.892 & $0.000^{* * *}$ & 0.060 & $0.018^{* *}$ & -0.081 & 0.526 & -0.241 & 0.109 & 0.130 & $0.008^{* * *}$ & 0.033 & 0.235 & 0.057 & $0.025^{* *}$ \\
\hline Gold & 0.068 & $0.005^{* * *}$ & -- & -- & -0.020 & 0.290 & 0.403 & $0.001^{* * *}$ & 0.075 & 0.384 & -0.041 & 0.701 & -0.074 & 0.265 & 0.039 & $0.014^{* *}$ & -0.011 & 0.556 \\
\hline JPY & 0.643 & $0.000^{* * *}$ & $\overline{0} 0.019$ & 0.295 & -- & -- & -0.044 & $0.009^{* * *}$ & 0.021 & 0.834 & 0.332 & $0.009^{* * *}$ & -0.084 & $0.007^{* * *}$ & 0.034 & $0.081^{*}$ & -0.035 & $0.078^{* *}$ \\
\hline Silver & 0.079 & $0.064^{*}$ & 0.703 & $0.000^{* * *}$ & -0.081 & $0.033^{* *}$ & -- & -- & -0.083 & 0.454 & 0.109 & 0.378 & -0.231 & 0.274 & -0.041 & $0.047^{* *}$ & 0.032 & 0.268 \\
\hline ТВ30 & $\overline{0} .003$ & 0.528 & 0.003 & 0.382 & 0.001 & 0.834 & -0.002 & 0.443 & -- & -- & 0.830 & $0.000^{* * *}$ & 0.010 & 0.164 & 0.011 & $0.001^{* * *}$ & -0.004 & 0.402 \\
\hline TN10 & $\overline{-} 0.006$ & 0.104 & $\overline{0} 0.001$ & 0.704 & 0.012 & $0.007^{* * *}$ & 0.002 & 0.372 & 0.627 & $0.000^{* * *}$ & -- & -- & -0.009 & 0.124 & 0.018 & $0.000^{* * *}$ & -0.004 & 0.228 \\
\hline WTI & 0.041 & $0.007^{* * *}$ & 0.030 & 0.239 & -0.036 & $0.008^{* * *}$ & -0.055 & 0.336 & 0.092 & 0.143 & -0.113 & 0.127 & -- & -- & -0.007 & 0.340 & 0.013 & 0.236 \\
\hline ZNM1 & 0.055 & 0.228 & 0.086 & $0.015^{* *}$ & 0.078 & $0.098^{*}$ & -0.051 & $0.023^{* *}$ & 0.531 & $0.006^{* * *}$ & 1.163 & $0.000^{* * *}$ & -0.040 & 0.380 & -- & -- & 0.921 & $0.000^{* * *}$ \\
\hline ZTM1 & 0.072 & $0.024^{* *}$ & $\overline{-} \mathbf{0} 019$ & 0.560 & -0.062 & $0.085^{*}$ & 0.031 & 0.200 & -0.131 & 0.426 & -0.199 & 0.233 & 0.052 & 0.278 & 0.708 & $0.000^{* * *}$ & -- & -- \\
\hline
\end{tabular}

Note: Resp.: Response i.e., parameter estimate in the regression model in Equation (2). Safe havens considered include Swiss Franc relative to the US Dollar (CHF), Japanese Yen to the US Dollar (JPY), Gold, Silver, West Texas Intermediate oil (WTI), 2-, 5-, 10-year US Treasury Notes and US Treasury Bonds (i.e., ZTM1, ZNM1, TN10, and TB30, respectively. ***; **; * indicates significance at 1, 5 and $10 \%$ respective. 